\title{
MJN \\ OUTCOME OF MENTORSHIP PROGRAMS BASED ON SIX SPECIFIC CRITERIA OF REGISTERED NURSES IN MALAYSIA
}

\author{
Salizar Mohamed Ludin \\ Department of Critical care Nursing, Kulliyyah of Nursing, International Islamic University \\ Malaysia, Pahang, Malaysia
}

Corresponding Author's Email:msalizar@iium.edu.my

\begin{abstract}
Background: Mentoring of new staff nurses is frequently performed. Internationally researches have reported that this exercise helped the new staff to retain information better, adopt a professional conduct, and be more satisfied with their jobs. Mentoring programmes are usually conducted to encourage cooperation as well as socialisation among the new registered nurses (RNs) in specific units or organisations. Aim: This research aims to evaluate the outcome of mentorship programs based on six specific criteria and nurses' willingness to stay in the profession in hospital settings. Method: A comparative cross-sectional study designed via convenience sampling was conducted in nine hospitals using the self-administered mentorship for nurses (MNMSN) questionnaire. Findings: A total of 593 respondents were recruited, mostly female (87.6\%), under 25 years old $(84.7 \%)$, from Malay $(71 \%)$ and highest nursing education of diploma level (99.2\%). The predisposing factors that influence performance for pre- and post-program are 'patients assessment' (mean=4.763, S.D $=0.52$ and mean=4.733, S.D=0.536); 'clinical decision' (mean=4.722, S.D =0.527 and mean $=4.73, \mathrm{~S} . \mathrm{D}=0.54$ ); 'cultural competencies' (mean=4.42, $\mathrm{S} . \mathrm{D}=0.443$ as well as mean=4.354, $\mathrm{S} . \mathrm{D}=0.442$ ); and 'professionalism' (mean=4.764, S.D $=0.533$ and mean $=4.698, \mathrm{~S} . \mathrm{D}=0.563$ ) respectively. Each predisposing factor showed a significant correlation (strong and moderately positive). Overall result for 'willingness to stay' is significant $[\mathrm{F},(5,585)=556.308, p<0.05]$ pre-program compared to post-program (willingness to stay is significantly correlated $[\mathrm{F}(5,585)=544.907, p<0.05]$. Discussion: The mentorship program showed a positive transition among new nurses to start their nursing career. They somewhat agree with all statements regarding patient's assessment skill, clinical decision making, professionalism, positive feeling and willingness to continue working as a nurse. However, according to several nurses admitted, their cultural competency and sensitivity were somewhat low and challenging. Conclusion: Mentor-mentee programmes can improve new RNs' willingness to stay and increase retention. Nurses were able to face greater challenges to provide cultural and linguistically appropriate healthcare services. Therefore, guidance by the mentor should be given highest emphasis.
\end{abstract}

\section{Keywords: Nurse Mentor Program, Mentoring, Professionalism, Retention}

\section{INTRODUCTION}

Healthcare sector workers know that the workforce is likely to be insufficient in the future. The nursing field is not going to be spared from the anticipated quandary. As per Heinen et al., (2013), around 9\% of European nurses had the intention to quit their jobs. Evidently, older RNs reportedly had fewer intentions to do so, relative to the younger ones (Cortese, 2012). Based on the Nurses' Early Exit from the research by van Der Heijden et al., (2009) it was found that nurses of the age group 25-35 years had the greatest intentions to quit the service in the majority of European nations.

Malaysia is no stranger to the above-mentioned problem, because the population which is growing old and increasingly suffering from non-communicable ailments poses greater demands for nursing staff as well 
as community welfare services. However, in light of the rise of more lucrative jobs for nurses as well as ageing of the workforce (mean age: 40.5 years), qualified nurses are declining in numbers (Nursing \& Midwifery Council, 2017). The local nursing sector accounts for the largest proportion of the healthcare sector, with a manpower of 79700 (Siew, Chitpakdee \& Chontawan, 2011). However, its turnaround rate has jumped by over $50 \%$ from 2005 to 2010, with 400 nurses leaving the profession in 2005 and 1,049 nurses leaving in 2010 (Barnett, Namasivayam \& Narudin, 2010).

The retainment of fresh-graduate $\mathrm{RNs}$ in critical care institutions is a major hurdle. These new staff are reportedly dissatisfied and disappointed with their jobs as well as the profession in general, leading to high rates of attrition (Kovner \& Djukic, 2009). The cost of new nurse attrition is borne by healthcare organisations. Recognising the need for strategies to improve the retention of new nurses, the Academy of MedicalSurgical Nurses (AMSN) developed the Nurses Nurturing Nurses (N3) mentorship programme in 2003. The project was aimed to improve the nurses' work satisfaction as well as intention to continue serving, thus improving retention. The N3 programme was founded with the aim to examine the impact of mentorship programmes with regards to the new RNs' confidence, intentions to remain in the profession, as well as to increase the contentment with their work, mentors, and also with the aforementioned programme.

The new nurses' intentions to quit, as well as the motivations necessary must be investigated appropriately. Apparently, RN turnaround ought to be examined with respect to a generation-based view since the aspects which motivate the RNs to quit differed with different age groups. In general, all generations are motivated by the economy, commitment, role models, community support, as well as financial remunerations (Tei-Tominaga, Asakura \& Asakura, 2018). According to research, there are novel methods at the social as well as healthcare system levels to promote the retainment of younger RNs. While previous studies have proven the benefits of mentoring programmes regarding improvement of nursing skills and attitudes, there is little research on these programmes' influencing nurses' willingness to stay in the profession. The current study was aimed to determine whether mentormentee programmes will influence the willingness to stay or increase retention rate for new RNs and identify factors that contribute towards the willingness to stay as an outcome of the mentorship programme through a survey of new RNs in general hospitals in Malaysia.

\section{METHODOLOGY}

A cross-sectional study was conducted at nine different hospitals in Malaysia over a four-month period. The participants consisted of nurses who had recently commenced work at Ministry of Health $(\mathrm{MOH})$ hospitals. The self-administered mentorship for nurses (MNMSN) (Witter, 2012) questionnaire was distributed to participants who met the inclusion criteria: newly graduated or recently joined the nursing workplace, permanent and working on shift, full time. Those on long-term leave were excluded.

This questionnaire consisted of two parts: demographic data (age, gender, ethnicity, discipline, cultural affiliation, and nursing education qualification) and six specific criteria ( 7 items on patient assessment, 12 items on clinical decision making, 6 items on cultural competency, 11 items on professionalism, 5 items on positive feelings, and 6 items on willingness to continue the job). The questionnaire was tested on 20 subjects. The reliability and validity of this analysis showed that all criteria had a high value for Cronbach's alpha (0.639 to 0.904$)$. The six specific criteria were represented by a six-point Likert scale which scores ranged from "strongly disagree" (1) to "strongly agree" (6). The data were descriptively and inferentially analysed using Statistical Package for Social Science (SPSS) version 22.

This research was approved by the International Islamic University Malaysia, relevant hospital directors, and the Malaysian Medical Research Ethics Committee. Ethics-related issues were reviewed several times throughout the research to maximise protection of the participants' rights. The research objectives and processes, as well as the right to withdraw, were described to the participants. The individuals who filled and returned the questionnaires were considered to take part in the study with informed consent.

\section{RESULTS}

\section{Nurses'Demographic Characteristics}

In this study, nurses from nine hospitals were selected: 
HKL (32.7\%), HTAR Klang (22.3\%), Hospital Penang (14.8\%), HQE Sabah (14.2\%), Hospital Tuanku Jaafar Negeri Sembilan (7.9\%), Hospital Kuching Sarawak (3.4\%), Hospital Melaka (2.7\%), Hospital Putrajaya $(1.2 \%)$ and from Hospital Tuanku Fauziah, Perlis $(0.8 \%)$. In total, there were 593 respondents in the mentorship programme, with 520 female nurses and 73 male nurses. In that pool, $84.7 \%$ were under 25 years old. The cultural backgrounds of respondents include Malay (71\%), Indian (2.9\%), Chinese (1.7\%) and 'other' $(24.5 \%)$. Most participants were from the Medical discipline, followed by Accident \& Emergency and Intensive Care Unit, then Paediatrics. Most of the nurses have a Diploma in Nursing and only $0.8 \%$ of them have other qualifications (Table 1 ).

\section{Table 1: Distribution of Participants'Sociodemographic Characteristics}

\begin{tabular}{|c|c|c|c|}
\hline \multicolumn{2}{|c|}{ Demographic Characteristics } & $\begin{array}{l}\text { Frequency } \\
\text { (n) }\end{array}$ & $\begin{array}{c}\text { Percentage } \\
(\%)\end{array}$ \\
\hline \multirow[t]{9}{*}{ Hospital } & HKL & 194 & 32.7 \\
\hline & HTAR Klang & 132 & 22.3 \\
\hline & H. Penang & 88 & 14.8 \\
\hline & HQE Sabah & 84 & 14.2 \\
\hline & H. Tuanku Jaafar N9 & 47 & 7.9 \\
\hline & H. Kuching Sarawak & 20 & 3.4 \\
\hline & H. Melaka & 16 & 2.7 \\
\hline & H. Putrajaya & 7 & 1.2 \\
\hline & H. Tuanku Fauziah Perlis & 5 & 0.8 \\
\hline \multirow[t]{4}{*}{ Age } & Less than 25 years & 502 & 84.7 \\
\hline & $26-36$ years & 85 & 14.3 \\
\hline & $37-50$ years & 5 & 0.8 \\
\hline & More than 50 years & 1 & 0.2 \\
\hline \multirow[t]{2}{*}{ Gender } & Male & 73 & 12.3 \\
\hline & Female & 520 & 87.7 \\
\hline \multirow[t]{19}{*}{ Discipline } & Medical & 133 & 22.4 \\
\hline & Surgical & 35 & 5.9 \\
\hline & $\begin{array}{l}\text { Accident \& } \\
\text { Emergency }\end{array}$ & 54 & 9.1 \\
\hline & Psychiatric & 13 & 2.2 \\
\hline & HDU & 22 & 3.7 \\
\hline & Geriatric & 2 & 0.3 \\
\hline & Paediatric & 50 & 8.4 \\
\hline & Plastic & 7 & 1.2 \\
\hline & Burn unit & 4 & 0.7 \\
\hline & Orthopaedic & 37 & 6.2 \\
\hline & Neurology & 46 & 7.8 \\
\hline & Haematology & 10 & 1.7 \\
\hline & Respiratory & 11 & 1.9 \\
\hline & Dermatology & 1 & 0.2 \\
\hline & CSSD & 2 & 0.3 \\
\hline & Dengue Ward & 1 & 0.2 \\
\hline & ENT & 6 & 1.0 \\
\hline & Intensive Care Unit (ICU) & 54 & 9.1 \\
\hline & Cardiac Care Unit (CCU) & 4 & 0.7 \\
\hline
\end{tabular}

\begin{tabular}{|l|l|c|c|}
\hline \multirow{5}{*}{} & Oncology & 10 & 1.7 \\
\cline { 2 - 4 } & Urology & 24 & 4 \\
\cline { 2 - 4 } & Rehabilitation unit & 5 & 0.8 \\
\cline { 2 - 4 } & Ophthalmology & 3 & 0.5 \\
\cline { 2 - 4 } & Operation Theatre & 33 & 5.6 \\
\cline { 2 - 4 } & Obstetrics \& Gynaecology & 10 & 1.7 \\
\cline { 2 - 4 } & Nephrology & 16 & 2.7 \\
\hline \multirow{4}{*}{$\begin{array}{l}\text { Nursing } \\
\text { Education } \\
\text { Qualification }\end{array}$} & Diploma in Nursing & 588 & 99.2 \\
\cline { 2 - 4 } & Other qualifications & 5 & 0.8 \\
\hline
\end{tabular}

\section{The Comparison of Predisposing Factors Pre-and Post-Mentorship Programme based on mean score}

Six predisposing aspects influenced the outcome and performances between the pre- and post-programme groups: patient-assessment, clinical decision-making, cultural competencies, professionalism, positive feeling, as well as willingness to stay.

\section{Patient Assessment}

According to the result, the nurse's response to their ability to do patients' assessment (pre-and postmentoring) as somewhat agree, (mean $=4.763$, $\mathrm{S} . \mathrm{D}=0.52)$ and (mean=4.733, $\mathrm{S} . \mathrm{D}=0.536)$ respectively. In detail, the pre and post findings show the mean value where the respondents somewhat agreed with all statements regarding patient assessment except for items 1, 2 and 3 for post finding where most of them agree with the respective statement. Based on the highest mean value, post-mentoring, most respondents chose 'agree' for item three, "I collect subjective and objective data from the patient to effectively plan interventions" (mean=5.03, S.D=0.746) and prementoring, the respondents somewhat agree with item one, "When caring for patients, I ask what are their main concerns" (mean=4.95, S.D=0.773). Meanwhile, the lowest mean post-mentoring is 'somewhat agree' with item five, "I know how to activate the hospital's emergency and rapid response team" (mean $=4.39$, $\mathrm{S} . \mathrm{D}=0.808$ ) and pre-mentoring, the respondents somewhat agree on item four, "I can independently complete an overview of a head to toe physical assessment of a patient" (mean $=4.45, \mathrm{~S} . \mathrm{D}=0.882$ ).

\section{Clinical Decision Making (Decision-making, leadership, confidence level)}

The results showed that pre- and post-mentoring give mean values where the respondents somewhat agree, $($ mean $=4.722, \mathrm{~S} . \mathrm{D}=0.527)$ and $($ mean $=4.73$, 
$\mathrm{S} . \mathrm{D}=0.54)$ respectively. Pre- and post-mentoring gives mean values where most of the participants somewhat agree with the statements regarding clinical decision making. The highest mean value pre-mentoring was 'somewhat agree' for item 11, "I choose appropriate health education for my patients to facilitate informed decision" mean=4.87, S.D=0.693and for postmentoring, the respondents chose 'somewhat agree' for item one, "I recognise signs and symptoms of a deteriorating patient" (mean $=4.89, \mathrm{~S} . \mathrm{D}=0.693)$. The lowest mean value both pre- and post-mentoring was 'somewhat agree' with item seven, "I contribute to clinical decision making with the interdisciplinary team", $($ mean $=4.40, \mathrm{~S} . \mathrm{D}=0.810)$ and (mean $=4.49$, $\mathrm{S} . \mathrm{D}=0.780)$ respectively.

\section{Cultural Competency}

The results show that the respondents somewhat agree, pre- and post-mentoring, with values of mean=4.42, S.D=0.443 and mean=4.354, S.D=0.442 respectively. Pre- and post-mentoring give a mean value where most of the respondents somewhat agree with all statements regarding cultural competency except item one, which the respondents disagree with pre- and post-mentoring; item four, which the respondents somewhat disagree with pre- and postmentoring; and item six, which the respondents agree with pre-mentoring.

Based on the highest mean value, pre- and postmentoring, the participants chose 'somewhat agree' for item nine, "I am enthusiastic about doing my job well", $(\mathrm{mean}=5.09$, S.D. $=0.712$ and mean $=4.93$, S.D. $=0.77)$ respectively. The lowest mean value for pre- and postmentoring is 'disagree' on item one, "I am not always able to meet the cultural needs of the patients", $(\mathrm{mean}=2.8$, S.D. $=1.025$ and mean $=2.73$, S.D. $=0.986$ respectively).

\section{Professionalism}

The results show that the mean response pre- and post-mentoring is 'somewhat agree' with values of mean $=4.764$, S.D. $=0.533$ and mean $=4.698$, S.D. $=0.563$ respectively. Pre- and post-mentoring, most respondents somewhat agree with all statements regarding professionalism except for items 6 and 11, which most respondents agreed with pre-mentoring. Based on the highest mean value, pre-mentoring chose 'somewhat agree' for item 11,"I feel a strong commitment to practice in accord with the standards of the Nurse Practice Act" (mean=5.06, S.D=0.72) and for post mentoring, the respondents chose 'somewhat agree' for item six, "I show respect for patient and family cultural values by listening carefully to how one describes his or her illness" (mean=4.95, S.D=0.773). The lowest mean value pre- and post-mentoring was 'somewhat agree' on item two, "I ask patients about their beliefs regarding pain medications" at mean $=4.36, \mathrm{~S} . \mathrm{D}=0.969$ and mean $=4.41, \mathrm{~S} . \mathrm{D}=0.992$.

\section{Positive Feeling}

The results show that pre- and post-mentoring surveys give mean values which show that the respondents somewhat agree; $($ mean $=4.941, \mathrm{~S} . \mathrm{D}=0.648)$ and (mean=4.843, S.D $=0.711)$ respectively. Pre- and post-mentoring give a mean value where most of the respondents somewhat agree with all statements regarding positive feeling. Based on the highest mean value, pre-mentoring chose 'somewhat agree' for item one, "I feel supported in my role as a staff nurse" (mean=4.99, S.D=0.747) and, for post-mentoring, they chose 'somewhat agree' on item two, "My job provides me with meaningful work that motivates me to stay in nursing" (mean=4.91, S.D=0.80). For the lowest mean value, pre- and post-mentoring chose 'somewhat agree' on item one, "Because I feel valued to voice my concerns, I will remain in the nursing profession", (mean $=4.85$, $\mathrm{S} . \mathrm{D}=0.859)$ and $($ mean $=4.73, \mathrm{~S} . \mathrm{D}=0.88)$.

\section{Willingness to Stay}

The results showed that pre-and post-mentoring give mean values where the respondents somewhat agree, $($ mean $=4.905$, S.D $=0.661)$ and $($ mean $=4.960$, $\mathrm{S} . \mathrm{D}=0.804$ ) respectively. Pre- and post-mentoring, most of the respondents somewhat agree with all statements regarding willingness to stay except for item one for both groups and item three for the pre-mentoring group. According to the highest mean value, pre- and postmentoring chose to agree for item one, "I would like to continue working in the nursing profession", (mean=5.06, S.D $=0.822$ ) and (mean=5.03, S.D =0.751). For the lowest mean value, pre-and post-mentoring chose 'somewhat agree' on item two, "I think I am very adept and competent and willing to remain in nursing" (mean=4.54, S.D $=0.871$ and mean=4.92, $\mathrm{S} . \mathrm{D}=0.794$ ).

The Relationship between the Predisposing Factor Affecting the Outcome and Performance 


\section{Pre-mentorship programme}

Table 2 shows the results of correlating the mean score pre-mentoring for the six criteria. As indicated by the r-value, patient assessment is strongly positive and significantly correlated with clinical decision making $(r=0.834, p=0.001)$ and professionalism $(r=0.732, p$ $=0.001)$. Patient assessment is also moderately positive and significantly correlated with cultural competency $(r=0.503, p=0.001)$, positive feeling $(r=0.554$, $p=0.001)$, as well as willingness to stay $(r=0.524$, $p=0.001)$. In addition, clinical decision making showed a moderately positive and significant correlation with cultural competency $(r=0.574, p=0.001)$, positive feeling $(r=0.603, p=0.001)$ as well as willingness to stay
( $r=0.565, p=0.001)$. Clinical decision making was also strongly positively as well as significantly correlated with professionalism $(r=0.794, p=0.001)$. Cultural competency was strongly positively as well as significantly correlated with professionalism $(r=0.7$, $p=0.001$ ), and a moderately positive and significant correlation with positive feeling $(r=0.629, p=0.001)$ as well as willingness to stay $(r=0.560, p=0.001)$. Professionalism showed a moderately positive and significant correlation with positive feeling $(r=0.696$, $p=0.001)$ as well as willingness to stay $(r=0.631$, $p=0.001)$. Finally, positive feeling showed a strongly positive and significant correlation with willingness to stay $(r=0.907, p=0.001)$.

Table 2: Correlation of the predisposing factors affecting the outcome and performance pre-mentoring programme

\begin{tabular}{|c|c|c|c|c|c|c|}
\hline Factor & $\begin{array}{l}\text { Patient } \\
\text { Assessment }\end{array}$ & $\begin{array}{l}\text { Clinical } \\
\text { Decision }\end{array}$ & $\begin{array}{l}\text { Cultural } \\
\text { Competency }\end{array}$ & $\begin{array}{l}\text { Professio } \\
\text { nalisms }\end{array}$ & $\begin{array}{l}\text { Positive } \\
\text { Feeling }\end{array}$ & $\begin{array}{l}\text { Willingness } \\
\text { to Stay }\end{array}$ \\
\hline $\begin{array}{l}\text { Patient } \\
\text { Assessment }\end{array}$ & & $\begin{array}{l}0.834 \\
(0.000)\end{array}$ & $\begin{array}{l}0.503 \\
(0.000)\end{array}$ & $\begin{array}{l}0.732 \\
(0.000)\end{array}$ & $\begin{array}{l}0.554 \\
(0.000)\end{array}$ & $\begin{array}{l}0.524 \\
(0.000)\end{array}$ \\
\hline $\begin{array}{l}\text { Clinical } \\
\text { Decision }\end{array}$ & $\begin{array}{l}0.834 \\
(0.000)\end{array}$ & & $\begin{array}{l}0.574 \\
(0.000)\end{array}$ & $\begin{array}{l}0.794 \\
(0.000)\end{array}$ & $\begin{array}{l}0.603 \\
(0.000)\end{array}$ & $\begin{array}{l}0.565 \\
(0.000)\end{array}$ \\
\hline $\begin{array}{l}\text { Cultural } \\
\text { Competency }\end{array}$ & $\begin{array}{l}0.503 \\
(0.000) \\
\end{array}$ & $\begin{array}{l}0.574 \\
(0.000) \\
\end{array}$ & & $\begin{array}{l}0.7 \\
(0.000) \\
\end{array}$ & $\begin{array}{l}0.629 \\
(0.000) \\
\end{array}$ & $\begin{array}{l}0.560 \\
(0.000) \\
\end{array}$ \\
\hline Professionalism & $\begin{array}{l}0.732 \\
(0.000) \\
\end{array}$ & $\begin{array}{l}0.794 \\
(0.000) \\
\end{array}$ & $\begin{array}{l}0.7 \\
(0.000) \\
\end{array}$ & & $\begin{array}{l}0.696 \\
(0.000)\end{array}$ & $\begin{array}{l}0.631 \\
(0.000) \\
\end{array}$ \\
\hline $\begin{array}{l}\text { Positive } \\
\text { Feeling }\end{array}$ & $\begin{array}{l}0.554 \\
(0.000) \\
\end{array}$ & $\begin{array}{l}0.603 \\
(0.000) \\
\end{array}$ & $\begin{array}{l}0.629 \\
(0.000)\end{array}$ & $\begin{array}{l}0.696 \\
(0.000)\end{array}$ & & $\begin{array}{l}0.907 \\
(0.000) \\
\end{array}$ \\
\hline $\begin{array}{l}\text { Willingness } \\
\text { To Stay }\end{array}$ & $\begin{array}{l}0.524 \\
(0.000)\end{array}$ & $\begin{array}{l}0.565 \\
(0.000)\end{array}$ & $\begin{array}{l}0.560 \\
(0.000)\end{array}$ & $\begin{array}{l}0.631 \\
(0.000)\end{array}$ & $\begin{array}{l}0.907 \\
(0.000)\end{array}$ & \\
\hline
\end{tabular}

\section{Post-mentorship program}

Table 3 shows the results of correlating the mean score post-mentoring of the six criteria: patient assessment, clinical decision making, cultural competence, professionalism, positive feeling, and willingness to stay. As indicated by the $r$-value, patient assessment is strongly positive and significantly correlated with clinical decision making $(r=0.846, p=$ $0.001)$ and professionalism $(r=0.734, p=0.001)$. Patient assessment has a moderately positive and significant correlation with cultural competency $(r=0.592$, $p=0.001)$, positive feeling $(r=0.574, p=0.001)$, and willingness to stay ( $r=0.573, p=0.001)$. In addition, clinical decision making showed a moderately positive and significant correlation with cultural competency $(r$
$=0.646, p=0.001)$, positive feeling $(r=0.634, p=0.001)$, as well as willingness to stay $(r=0.602, p=0.001)$. Clinical decision making also showed a strongly positively as well as significantly correlated with professionalism $(r=0.808, p=0.001)$. Then, cultural competency showed a strongly positively as well as significantly correlated relation with professionalism $(r=0.740, p=0.001)$ and a moderately positive and significant correlation with positive feeling $(r=0.617$, $p=0.001)$ and willingness to stay $(r=0.595, p=0.001)$. Professionalism had a strongly positive and significant correlation with positive feeling $(r=0.723, p=0.001)$ and willingness to stay $(r=0.704, p=0.001)$. Finally, positive feeling showed a strongly positive and significant correlation with willingness to stay $(r=0.903, p=0.001)$. 
Table 3: Correlation of the predisposing factors affecting the outcome and performance post-mentoring programme

\begin{tabular}{|c|c|c|c|c|c|c|}
\hline Factor & $\begin{array}{l}\text { Patient } \\
\text { Assessment }\end{array}$ & $\begin{array}{l}\text { Clinical } \\
\text { Decision }\end{array}$ & $\begin{array}{l}\text { Cultural } \\
\text { Competency }\end{array}$ & Professionalisms & $\begin{array}{l}\text { Positive } \\
\text { Feeling } \\
\end{array}$ & $\begin{array}{l}\text { Willingness } \\
\text { To Stay }\end{array}$ \\
\hline $\begin{array}{l}\text { Patient } \\
\text { Assessment }\end{array}$ & & $\begin{array}{c}0.846 \\
(0.000)\end{array}$ & $\begin{array}{c}0.592 \\
(0.000)\end{array}$ & $\begin{array}{c}0.734 \\
(0.000) \\
\end{array}$ & $\begin{array}{c}0.574 \\
(0.000)\end{array}$ & $\begin{array}{c}0.573 \\
(0.000) \\
\end{array}$ \\
\hline $\begin{array}{l}\text { Clinical } \\
\text { Decision }\end{array}$ & $\begin{array}{c}0.846 \\
(0.000) \\
\end{array}$ & & $\begin{array}{c}0.646 \\
(0.000) \\
\end{array}$ & $\begin{array}{c}0.808 \\
(0.000) \\
\end{array}$ & $\begin{array}{c}0.634 \\
(0.000)\end{array}$ & $\begin{array}{c}0.602 \\
(0.000)\end{array}$ \\
\hline $\begin{array}{l}\text { Cultural } \\
\text { Competency }\end{array}$ & $\begin{array}{c}0.592 \\
(0.000) \\
\end{array}$ & $\begin{array}{c}0.646 \\
(0.000) \\
\end{array}$ & & $\begin{array}{c}0.740 \\
(0.000) \\
\end{array}$ & $\begin{array}{c}0.617 \\
(0.000) \\
\end{array}$ & $\begin{array}{c}0.595 \\
(0.000) \\
\end{array}$ \\
\hline Professionalisms & $\begin{array}{c}0.734 \\
(0.000) \\
\end{array}$ & $\begin{array}{c}0.808 \\
(0.000) \\
\end{array}$ & $\begin{array}{c}0.740 \\
(0.000) \\
\end{array}$ & & $\begin{array}{c}0.723 \\
(0.000) \\
\end{array}$ & $\begin{array}{c}0.704 \\
(0.000) \\
\end{array}$ \\
\hline $\begin{array}{l}\text { Positive } \\
\text { Feeling }\end{array}$ & $\begin{array}{c}0.574 \\
(0.000) \\
\end{array}$ & $\begin{array}{c}0.634 \\
(0.000) \\
\end{array}$ & $\begin{array}{c}0.617 \\
(0.000) \\
\end{array}$ & $\begin{array}{c}0.723 \\
(0.000) \\
\end{array}$ & & $\begin{array}{c}0.903 \\
(0.000) \\
\end{array}$ \\
\hline $\begin{array}{l}\text { Willingness } \\
\text { To Stay }\end{array}$ & $\begin{array}{c}0.573 \\
(0.000) \\
\end{array}$ & $\begin{array}{c}0.602 \\
(0.000) \\
\end{array}$ & $\begin{array}{c}0.595 \\
(0.000) \\
\end{array}$ & $\begin{array}{c}0.704 \\
(0.000) \\
\end{array}$ & $\begin{array}{c}0.903 \\
(0.000) \\
\end{array}$ & \\
\hline
\end{tabular}

Regression tests were conducted to examine the correlation between the willingness to stay and six predisposing factors. Table 4 represents the overall sample of willingness to stay pre-mentoring. Based on the ANOVA test, the overall of willingness to stay is significant $[\mathrm{F}(5,585)=556.308, p<0.05]$. The multiple regressions showed that there is a significant correlation between positive feeling and willingness to stay. The results explain that $90.9 \%$ of the willingness to stay responses are due to positive feelings and the remaining $9.1 \%$ indicates other factors.

Table 4: The relationship between the predisposing factor affecting the outcome and performance prementoring programme

\begin{tabular}{|l|c|c|c|c|c|}
\hline & \multicolumn{2}{|c|}{$\begin{array}{c}\text { Unstandardized } \\
\text { Coefficients }\end{array}$} & $\begin{array}{c}\text { Standardised } \\
\text { Coefficients }\end{array}$ & & \\
\hline & $\mathrm{B}$ & $\mathrm{SE}$ & $\mathrm{B}$ & $\mathrm{T}$ & $\mathrm{Sig}$ \\
\hline Constant & 0.311 & 0.204 & & 2.467 & 0.014 \\
\hline $\begin{array}{l}\text { Patient } \\
\text { Assessment }\end{array}$ & 0.039 & 0.126 & 0.031 & 0.960 & 0.337 \\
\hline $\begin{array}{l}\text { Clinical Decision } \\
\text { Making }\end{array}$ & 0.030 & 0.040 & 0.024 & 0.672 & 0.502 \\
\hline $\begin{array}{l}\text { Cultural } \\
\text { Competency }\end{array}$ & -0.033 & 0.045 & -0.023 & -0.898 & 0.370 \\
\hline Professionalism & -0.31 & 0.037 & -0.025 & -0.728 & 0.467 \\
\hline Positive Feeling & 0.924 & 0.043 & 0.909 & 36.131 & 0.000 \\
\hline
\end{tabular}

Table 5 shows the sample's willingness to stay postmentoring. Based on the ANOVA test, the overall willingness to stay is significant $[\mathrm{F}(5,585)=544.907, p<$ $0.05]$. The multiple regressions showed that all factors have a significant correlation to willingness to stay. The results showed that $82.3 \%$ of the willingness to stay responses are due to all factors and $7.7 \%$ indicates other factors.
Table 5: The relationship between the predisposing factor affecting the outcome and performance postmentoring programme

\begin{tabular}{|l|c|c|c|c|c|}
\hline & \multicolumn{2}{|c|}{$\begin{array}{c}\text { Unstandardized } \\
\text { Coefficients }\end{array}$} & $\begin{array}{c}\text { Standardised } \\
\text { Coefficients }\end{array}$ & & \\
\hline & $\mathrm{B}$ & $\mathrm{SE}$ & $\mathrm{B}$ & $\mathrm{T}$ & $\mathrm{Sig}$ \\
\hline Constant & 0.186 & 0.13 & & 1.43 & 0.153 \\
\hline $\begin{array}{l}\text { Patient } \\
\text { Assessment }\end{array}$ & 0.125 & 0.044 & 0.095 & 2.877 & 0.004 \\
\hline $\begin{array}{l}\text { Clinical Decision } \\
\text { Making }\end{array}$ & -0.121 & 0.05 & -0.093 & -2.426 & 0.016 \\
\hline $\begin{array}{l}\text { Cultural } \\
\text { Competency }\end{array}$ & 0.025 & 0.042 & 0.016 & 0.593 & 0.044 \\
\hline Professionalism & 0.127 & 0.046 & 0.101 & 2.78 & 0.006 \\
\hline Positive Feeling & 0.816 & 0.025 & 0.824 & 32.033 & 0.000 \\
\hline$R=0.907$, R2 $=0.823$, Adjusted $R 2=0.822, F$-statistic $=544.907, p$-value $=0.000$
\end{tabular}

\section{DISCUSSION}

\section{Specific Criteria and Performance Post-Mentoring}

\section{Patients'Assessment Skill}

The total mean score post-mentoring increased and, as indicated by the $r$-value, patient assessment had a strongly positive and significant correlation with clinical decision making and professionalism. This result corresponds to a previous study which indicated that a positive transition among new nurses to start their nursing career where the findings showed correlations between pre-and post-programme as learning new skills requires progression through stages or levels; from a novice to a competent, proficient and expert nurse(American Association of Colleges of Nursing, 2017). Throughout the four-month programme, all novice nurses continued to experience the real world and progress to the advanced beginner and high levels 
of the continuum (Mariani, 2012).

New nurses worked with Clinical Practice Facilitators to improve job-related competencies as well as keep track of work issues like evidence-based practices, employees' morale, as well as being positive influencer (Kelly, Simpson, \& Brown, 2002).

\section{Clinical Decision-Making}

The definition of clinical decision-making is "a complex process involving information processing, critical thinking, evaluating evidence, applying relevant knowledge, problem-solving skills, reflection, and clinical judgement to select the best course of action which optimises a patient's health and minimises any potential harm" (Standing, 2010). In nursing, this factor denotes the procedure whereby the RNs collect patientrelated information, as well as assess and decide on the intervention to be administered (Clark, 1996).

At post-mentoring, most of the respondents somewhat agree with all statements regarding clinical decision making. Based on the highest mean value, the respondents chose 'somewhat agree' for "I recognise signs and symptoms of a deteriorating patient". The mentorship programme taught the novice nursing fundamentals so they could care for their patients appropriately through proper diagnoses, preparations of detailed nursing care plans, promotion of healthcare, as well as prompt rehabilitation (Benner, 2001). As healthcare needs are becoming increasingly complex, new graduate nurses will need to have sound clinical decision-making capabilities as well as leadership skills (Hnatiuk, 2012).

\section{Cultural Competency}

Cultural competency is a new and evolving concept in nursing and an emerging field of research. Cultural competencies refer to the methods of fostering awareness, empathy, acumen, skills, as well as communication between healthcare providers, apart from improving interaction with clients of various cultural backgrounds (St. Clair \& McKenry, 1999). 17

The lowest mean value pre- and post-mentoring was 'disagree' on item one, "I am not always able to meet the cultural needs of the patients". Malaysia is a multiracial and multicultural country which includes Malay, Indian, Chinese and multiple ethnicities from Sabah and Sarawak. Thus, it offers greater challenges to new nurses in the provision of healthcare services which befit the local culture and language while respecting their norms and culture such as traditional herbs and medicine along with languages (communication), religion and diets. An understanding of the cultural intricacies from the views of healthcare staff as well as recipients should prevail since they influence all facets of life. Thus, mentorship programmes should prepare new RNs to navigate the complexities in the provision of healthcare services that befit the cultures as well as languages of the community.

Nurses are responsible to provide culturally congruent care (Shinners, Ashlock, \& Brooks, 2014) which is both meaningful and satisfying, is appropriate for the community livelihoods, as well as enhances health and well-being. This level of service can only be delivered by healthcare staff who recognise the recipients' requirements (Ronsten, Andersson, \& Gustafsson, 2005).

\section{Professionalism}

Professional socialisation refers to intricate and interactional processes for the learning of professional aspects (which include knowledge, skills, as well as behaviours). It also entails the internalisation of the profession's values, conduct, objectives, and identities, in addition to the unique attributes of its members (Dinmohammadi, Peyrovi \& Mehrdad, 2013). Hence, professional socialisation - which entails the attainment of skills, know-how, occupational traits, values, identities, conventions, as well as self-concepts - is likely to be able to neutralise reality shocks. It is recommended for professional courses to cover the ethical, research, and professional aspects of nursing (Hisar, Karadağ, \& Kan, 2010). Such short-term courses as such may take place formally and informally. Role modelling as well as organisational cultural changes may work well in informal sessions (van Mook et al., 2009).

In addition, mentor's significant role is to shape their views to act as mentors, thus highlighting the importance of role modelling. An effective role model displays appropriate attitudes, values, and behaviours for the learning benefit of others (Scandura \& Williams, 2001).

When student nurses convert into graduate ones, they require (i) professional socialisation to combat 
reality shocks as well as support work-readiness; (ii) inter-personal relations to assist with inter-personal disagreements as well as provide organisation-based support; and (iii) work-environment factors (role models, superiors, amount of work, etc.) (Lewis et al., 2009).

\section{Positive Feeling}

Pre-and post-mentoring, the respondents somewhat agree with all statements regarding positive feeling. The highest mean value pre-mentoring was 'somewhat agree' with item one, "I feel supported in my roles as staff nurse". This result resembled that of a prior research, whereby workplace support constituted the chief aspect for reducing the intentions of nurses to quit (van Der Heijden et al., 2009). Work support is also positively associated with career advancement as it notably affects the workers' job explorations, goals, as well as strategies, which in turn benefit their professional advancement as well as self-contentment (Woods \& Lynn, 2014). Mentoring programmes are one way to provide a peer social support network for new employees (Wing, Regan, \& Spence Laschinger, 2015). The social support of an experienced nurse allows novice nurses to feel more confident in their new role more rapidly(Enrico, 2011).

There is a strong positive and significant correlation between positive feeling and willingness to stay. A strong concept of self can enhance selfconfidence and -worth, performance, as well learning experiences (Lewis et al., 2009). It is valuable as a critical mediator of key psychology- and behaviourrelated parameters like work satisfaction as well as organisational retainment (Greenwood, 2000).

\section{Variables associated with a new RN's willingness to remain in the Nursing Profession}

Willingness to remain in the nursing profession is determined by factors like going beyond expectations in terms of work commitment; distribution of knowledge and workload; as well as appreciation of the nurses' professional contributions (Witter \& Manley, 2013). The highest mean value post-mentoring was 'agree' with item one: "I would like to continue working in the profession of nursing". Effective mentoring reduces job burnout, decreases attrition rates and improves retention. Moreover, it enhances nursing satisfaction and ultimately improves patient outcomes by providing nurses with continuous support, guidance and encouragement to deal with the complexities encountered in their roles (Bérubé et al., 2012). Similarly, as per Duchscher (2008) mentoring new staff has helped them to retain information better, adopt a professional conduct, and be more satisfied with their jobs.

Our findings show that all factors are significantly related to willingness to stay post-mentoring. Therefore, cultural competency, positive feelings, clinical decision making, patient assessment, and professionalism are all predictors of nurses' willingness to stay. In terms of willingness to continue working as a nurse, pre-mentoring programme, positive feelings accounted for $90.9 \%$ of its variance. The work contentment of fresh graduate nurses across a variety of specialist fields, as well as their intention to continue serving as nurses have been evaluated. The results of which have indicated that the nurses who intended to do the aforementioned, experienced greater satisfaction over certain roles which they perceived to be crucial, namely rosters, colleagues, interaction, professional opportunities, acknowledgement, control and responsibility (Roberts, Jones \& Lynn, 2004).

However, the researchers expressed that graduate nurses were dissatisfied over their work surroundings and were frustrated over the perceived insufficiency of agency to affect change. Discontentment over wages and rosters, as well as lack of job advancement opportunities, were key areas of dissatisfaction (Halfer \& Graf, 2006). Previous study reported workloads as well as perceived care standards were factors related to RNs' intentions to leave their present institutions (Aiken et al., 2013). However, according to Heinen et al. (2013), these factors did not determine the intentions to quit the profession.

An Italian research reported that job scope and organisational practices were the strongest drivers of the intensive-care RNs' intentions to leave their current institutions. Meanwhile, their intentions to quit nursing were largely related to the status of the profession, pay, as well as organisational policies (Cortese, 2012). Moreover, as per another study, the former intentions were associated with organisational leaderships (Simon, Müller \& Hasselhorn, 2010), while the latter were related to individual backgrounds as well as worklife balance. Work contentment, organisational 
commitments, as well as desire to switch jobs were associated with intentions to seek new employers (Parry, 2008). Be that as it may, the current research has noted that the aforementioned desire corresponded with professional and organisational commitments.

\section{Mentor Programme Boosts New Nurses' Willingness to Stay in the Nursing Profession}

Retention is one of the key issues in patient safety and nurse satisfaction, which is why healthcare organisations are concerned over the retention and recruitment of new RNs. Evidently, while the population grows older and demands for advanced healthcare, more nurses will have to be retained. In 2004, the turnover rate of new RNs in a hospital and health centres exceeded $31 \%$, prompting the hospital's leaders to establish a commission to formulate a response. As per the literature, mentor-mentee programmes were an established method to reduce the $\mathrm{RN}$ turnover rate. Hence, the hospital subsequently developed such programmes in which the new staff were paired with senior ones (Fox, 2010).

Mentors have the ability to facilitate their mentees' professional socialisation, acclimatisation to the work environment and other such norms, as well as feelings of being appreciated by co-workers and the organisation (Beecroft et al., 2006). Additionally, the institutional know-how and standard can be imbued into the new staff by the mentors. As such, mentor-mentee programmes greatly help to retain new RNs (Greene \& Puetzer, 2002).

For the mentees, such programmes promote their advancement in the profession, provide various forms of job-related support, as well as improve teamwork during the delivery of service (Gibson \& Heartfield, 2005). The beneficial impact on the standard of care aside, mentor-mentee programmes help improve the new RNs' job performances and inculcate desirable organisational behaviours (Tourigny \& Pulich, 2005). Additionally, the mentees can get to know the ways to advance their careers, as well as seek psychological and job-related support from their seniors (McCloughen \& O' Brien, 2005).

Throughout these programmes, mentors frequently dole out difficult tasks to enhance the mentees' skills and knowledge. Otherwise, the former also offer careerrelated advice, assist in career advancements, help resolve work problems, as well as encourage the personal development of their mentees. As a result, the new staff can establish clearer perspectives with regards to professional advancement and development (Tourigny \& Pulich, 2005). Knowledge- and experience-sharing by the mentors have reportedly enhanced confidence levels, reduced anxieties, satisfied professional advancement requirements, as well as created significant levels of work contentment in their mentees (Underhill, 2006). Therefore, if mentoring programmes focus on role modelling, they can enhance the new RN's theoretical and practical know-how in an effective manner. Furthermore, mentoring facilitates the mentee's adaptation to contexts and roles associated with nursing.

\section{Limitations and future research suggestions}

Owing to the cross-sectional nature of this study, the extent of verification of the inter-construct associations were limited. Ergo, the effects of mentor-mentee programmes on RNs' performance are better determined via cohort studies. In addition, the comparison of the results pre- and post-mentoring only showed a slight increase in the overall means. This may be because the assessment was conducted after only four months of mentoring. It could be impractical to presume that new graduate nurses are ever ready to practise and acclimatise, build confidence levels, as well as apply their knowledge without supervision over such a short time. Thus, clinical excellence can be achieved through a longer mentorship programme as a training platform for the novice.

\section{CONCLUSION}

The current cross-sectional research has investigated the effects of mentoring programmes on RNs' willingness to continue serving as nurses. Evidently, these programmes have improved the willingness of the new RNs to stay, the retention of new RNs, as well as the access to psycho-social support and professional advancement advice. In an attempt to enhance the quality of mentor-mentee programmes, challenging tasks that provide new nurses with further learning opportunities need to be assigned. Effective mentoring reinforces the new RNs' work contentment, dedication to the institution, as well as motivation to continue being part of the profession. In this respect six factors positively influence the performance and willingness of 
new RNs to stay.

\section{ACKNOWLEDGEMENT}

I would like to thank the participants and those from nursing management who have contributed to this study. My special thanks also go to the International
Islamic University Malaysia and the Malaysia Ministry of Health for approval of the study to be conducted throughout Malaysia. Finally, my highest appreciation goes to the Director of Nursing Malaysia. Mdm. Rosena Abd. Ghani for her approval and facilitating the process of data collection in this study.

\section{REFERENCES}

Aiken, L.H., Sloane, D.M., Bruyneel, L., Van Den Heede, K. \& Sermeus, W. (2013). Nurses’ reports of working conditions and hospital quality of care in 12 countries in Europe. International Journal of Nursing Studies, 50(2), pp 143-153.

American Association of Colleges of Nursing (2017). Fact Sheet: Nursing Shortage. Retrieved from: https://www.aacnnursing.org/News-Information/Fact-Sheets/Nursing-Shortage

Barnett, T., Namasivayam, P. \& Narudin, D.A.A. (2010). A critical review of the nursing shortage in Malaysia, 57(1), pp 32-39.

Beecroft, P.C., Santner, S., Lacy, M.L., Kunzman, L. \& Dorey, F. (2006). New graduate nurses' perceptions of mentoring: Six-year programme evaluation. Journal of Advanced Nursing, 55(6), pp 736-747.

Benner, P.E. (2001). From novice to expert: excellence and power in clinical nursing practice (Commemorative ed. ed.). Upper Saddle River, NJ: Prentice Hall.

Bérubé, M., Valiquette, M., Laplante, É., Lepage, I., Belmonte, A., Tanguay, N., Lépine, I., Lalonde, L. \& Touchette, S. (2012). Nursing residency program: a solution to introduce new grads into critical care more safely while improving accessibility to services. Nursing Leadership, 25(1), pp 50-67.

Clark, R. (1996). Clinical decision-making by beginning nurses: A naturalistic study. (Doctor of Philosophy), Virginia Poytechnic Institute.

Cortese, C. (2012). Predictors of critical care nurses' intention to leave the unit, the hospital, and the nursing profession. Open Journal of Nursing, 2(3A), pp 311-326.

Dinmohammadi, M., Peyrovi, H. \& Mehrdad, N. (2013). Concept analysis of professional socialization in nursing. In Nursing forum, 48(1), pp 26-34.

Duchscher, J.B. (2008). A process of becoming: the stages of new nursing graduate professional role transition. Journal of continuing education in nursing, 39(10), pp 441-450.

Enrico, N.B. (2011). The Lived Experiences of Mentoring Nurses in Malaysia. Nurse Media: Journal of Nursing, $1(1), \mathrm{pp} 87-104$.

Fox, K.C. (2010). Mentor Program Boosts New Nurses' Satisfaction and Lowers Turnover Rate. The Journal of Continuing Education in Nursing, 41(7), pp 311-316.

Gibson, T. \& Heartfield, M. (2005). Mentoring for nurses in general practice: an Australian study. Journal of Interprofessional Care, 19(1), pp 50-62.

Greene, T.M. \& Puetzer, T.M. (2002). The Value of Mentoring: A Strategic Approach to Retention and Recruitment. Journal of Nursing Care Quality, 17(1), pp 63-70.

Greenwood, J. (2000). Critique of the graduate nurse: an international perspective. Nurse Education Today, 20(1), pp 17-23. 
Halfer, D. \& Graf, E. (2006). Graduate nurse perceptions of the work experience. Nursing Economics, 24(3), pp 150-156.

Heinen, M.M., van Achterberg, T., Schwendimann, R., Zander, B., Matthews, A., Kózka, M., Ensio, A., Sjetne, I.S., Moreno Casbas, T., Ball, J. \& Schoonhoven, L. (2013). Nurses' intention to leave their profession: A cross sectional observational study in 10 European countries. International Journal of Nursing Studies, 50(2), pp 174-184.

Hisar, F., Karadağ, A. \& Kan, A. (2010). Development of an instrument to measure professional attitudes in nursing students in Turkey. Nurse Education Today, 30(8), pp 726-730.

Hnatiuk, C. (2012). Mentoring nurses toward success. Minority Nurse. Retrieved from: https:// minoritynurse.com/mentoring-nurses-toward-success/

Kelly, D., Simpson, S. \& Brown, P. (2002). An action research project to evaluate the clinical practice facilitator role for junior nurses in an acute hospital setting. Journal of Clinical Nursing, 11(1), pp 90-98.

Kovner, C.T. \& Djukic, M. (2009). The Nursing Career Process From Application Through the First 2 Years of Employment. Journal of Professional Nursing, 25(4), pp 197-203.

Lewis, P., Dornan, T., Taylor, D., Tully, M., Wass, V. \& Ashcroft, D. (2009). Prevalence, Incidence and Nature of Prescribing Errors in Hospital Inpatients. Drug Safety, 32(5), pp 379-389.

Mariani, B. (2012). The effect of mentoring on career satisfaction of registered nurses and intent to stay in the nursing profession. Nursing research and practice, 2012(2012), pp 1-9.

McCloughen, A. \& O' Brien, L. (2005). Development of a mentorship programme for new graduate nurses in mental health. International Journal of Mental Health Nursing, 14(4), pp 276-284.

Nursing \& Midwifery Council (2017). New figures show an increase in numbers of nurses and midwives leaving the professions [Press release]. Retrieved from https://www.nmc.org.uk/news/press-releases/new-figuresshow-an-increase-in-numbers-of-nurses-and-midwives-leaving-the-professions

Parry, J. (2008). Intention to leave the profession: antecedents and role in nurse turnover. Journal of Advanced Nursing, 64(2), pp 157-167.

Robert, B.J., Jone, C. \& Lynn, M. (2004). Job Satisfaction of New Baccalaureate Nurses, JONA The Journal of Nursing Administration, 34(9), pp 428-435.

Ronsten, B., Andersson, E. \& Gustafsson, B. (2005). Confirming mentorship. Journal of Nursing Management, 13(4), pp 312-321.

Scandura, T.A. \& Williams, E. A. (2001). An Investigation of the Moderating Effects of Gender on the Relationships between Mentorship Initiation and Protege Perceptions of Mentoring Functions. Journal of Vocational Behavior, 59(3), pp 342-363.

Shinners, J., Ashlock, C. \& Brooks, Y. (2014). Implementation of a Standardized, Organizational Approach to Transition From Academics to Practice: A Case-Based Discussion. Nurse Leader, 12(3), pp 58-61.

Siew, P. L., Chitpakdee, B. \& Chontawan, R. (2011). Factors predicting organizational commitment among nurses in state hospital Malaysia. The International Medical Journal Malaysia, 10(2), pp 21-27.

Simon, M., Müller, B.H. \& Hasselhorn, H.M. (2010). Leaving the organization or the profession - a multilevel analysis of nurses' intentions. Journal of Advanced Nursing, 66(3), pp 616-626.

Standing, M. (2010). Clinical Judgement And Decision-Making In Nursing And Inter-Professional Healthcare: in Nursing and interprofessional healthcare. UK: Open University Press. 
St. Clair, A. \& McKenry, L. (1999). Preparing Culturally Competent Practitioners. Journal of Nursing Education, 38(5), pp 228-234.

Tei-Tominaga, M., Asakura, K. \& Asakura, T. (2018). Generation-Common and -Specific Factors in Intention to Leave among Female Hospital Nurses: A Cross-Sectional Study Using a Large Japanese Sample. International journal of environmental research and public health, 15(8), 1591.

Tourigny, L. \& Pulich, M. (2005). A Critical Examination of Formal and Informal Mentoring Among Nurses. The Health Care Manager, 24(1), pp 68-76.

Underhill, C.M. (2006). The Effectiveness of Mentoring Programs in Corporate Settings: A Meta-Analytical Review of the Literature. Journal of Vocational Behavior, 68(2), pp 292-307.

van Der Heijden, B.I.J.M., van Dam, K. \& Hasselhorn, H.M. (2009). Intention to leave nursing. Career Development International, 14(7), pp 616-635.

van Mook, W.N.K.A., de Grave, W.S., Wass, V., Sullivan, H., Zwaveling, J.H., Schuwirth, L.W. \& van Der Vleuten, C.P.M. (2009). Professionalism: Evolution of the concept. European Journal of Internal Medicine, 20(4), e81e84.

Wing, T., Regan, S. \& Spence Laschinger, H.K. (2015). The influence of empowerment and incivility on the mental health of new graduate nurses. Journal of Nursing Management, 23(5), pp 632-643.

Witter, J. (2012). Mentoring of medical surgical nurses, assessment of patients, clinical decision-making, cutlural competency, commitment to professional nursing standards, positive feelings about nursing at this hospital, and willingness to remain in the nursing profession. (Doctor of Education), Dowling College.

Witter, J. \& Manley, R. (2013). A quasi-experimental study: mentoring for the novice nurse in an acute care setting. Journal of Business and Economics, 4(5), pp 381-396.

Woods, A.M. \& Lynn, S.K. (2014). One Physical Educator's Career Cycle: Strong Start, Great Run, Approaching Finish. Research Quarterly for Exercise and Sport, 85(1), pp 68-80. 